\title{
Effect of Spirulina platensis and kelp on the antioxidant activity of wheat bread
}

\section{Denka Zlateva ${ }^{1}$, Petya Ivanova ${ }^{2}$, Rosen Chochkov ${ }^{2}$, Dana Stefanova ${ }^{1}$}

\author{
1 - University of Economics, Varna, Bulgaria \\ 2 - University of Food Technologies, Plovdiv, Bulgaria
}

Keywords:

Wheat bread

Spirulina platensis,

Kelp

Antioxidant

\section{Article history:}

Received 24.04.2020

Received in revised

form 21.06.2020

Accepted 30.09.2020

\section{Corresponding}

author:

Rosen Chochkov

E-mail:

rosen4o4kov@abv.bg

\section{DOI:}

$10.24263 / 2304-$

974X-2020-9-3-12

\section{Abstract}

Introduction. The effect of some edible seaweed (Spirulina platensis and Kelp) on the antioxidant activity of wheat bread was studied.

Materials and methods. Bread is obtained from wheat flour with the addition of Spirulina platensis and Kelp (powder) in the amount of 2 or $4 \%$ by the weight of flour. The antioxidant activity of ethanolic extracts was evaluated by three methods: FRAP (ferric reducing antioxidant power), DPPH (2,2-diphenyl-1picrylhydrazyl) radical scavenging method and hydroxyl radical (OH) scavenging assay (HRSA).

Results and discussion Significant differences in total polyphenol content were found among different quantities of Kelp and Spirulina platensis added in breads. The highest polyphenols content had bread sample containing 4\% Spirulina platensis: $0.88 \pm 0.02 \mathrm{mg} \mathrm{GAE} / \mathrm{g} \mathrm{DW}$, and the lowest - sample with $2 \%$ Kelp: $0.44 \pm 0.05 \mathrm{mg}$ GAE$/ \mathrm{g}$ DW. There is a correlation between DPPH radical scavenging activities and total polyphenol and flavonoid contents. The highest DPPH radical scavenging activity was measured in Spirulina supplemented bread (4\%) - 3.11 $\pm 0.05 \mathrm{mmol}$ $\mathrm{TE} / \mathrm{g}$ DW. In contrast, the lowest DPPH scavenging capacities was observed in ethanol extracts from bread with $4 \%$ Kelp $(0.89 \pm 0.02$ mmol TE/g DW). Antioxidant ability of ethanol extracts for reducing $\mathrm{Fe}^{3+}$ by the FRAP values reflecting the ranged from 2.77 (for the sample with $4 \%$ Kelp) to $5.04 \mu \mathrm{mol} \mathrm{Fe}{ }^{2+} / \mathrm{g}$ DW (for the sample with $4 \%$ Spirulina). With an increased S. platensis concentration, significant changes were noted in the hydroxyl radical scavenging activity. The highest values were $27.8 \pm 0.4 \mu \mathrm{g}$ $\mathrm{BHT} / \mathrm{g}$ DW in the sample prepared with $4 \%$ Spirulina platensis, and $17.16 \pm 0.42 \mu \mathrm{g}$ BHT/g DW in the bread containing $2 \%$ of the same algae. The result for the control sample was $13.85 \pm 0.37 \mu \mathrm{g}$ $\mathrm{BHT} / \mathrm{g}$ DW - higher value than the sample with $2 \% \mathrm{Kelp}$ $(11.85 \pm 0.42 \mu \mathrm{g} \mathrm{BHT} / \mathrm{g} \mathrm{DW})$ and $4 \%$ Kelp $(7.94 \pm 0.34 \mu \mathrm{g} \mathrm{BHT} / \mathrm{g}$ DW), as with other two methods for determining the antioxidant activity.

Conclusions Ethanol extracts from bread prepared with the addition of $4 \%$ Spirulina platensis had the highest content of phenolic compounds and antioxidant activity measured with all the methods used. 


\section{Introduction}

Oxidative stress can be defined as an excessive amount of reactive oxygen species (ROS), which is result of an imbalance between their production and destruction [2]. Different authors $[1,3,4]$ point that oxidative stress causes irreversible damage to protein, lipid and DNA that are involved in pathogenesis of major diseases such as cardiovascular disease, cancer, diabetes, neurological disorders, atherosclerosis, hypertension, ischemia/perfusion, acute respiratory distress syndrome, asthma and also aging. So different ways to reduce the oxidative stress need to be pointed out.

It is well known that lifestyle and nutrition might play an important role against environmental oxidant exposure and damage. One of the possibilities for prevention is the ingestion of protective ingredients from food, with dietary components having been reported to show protective effects against oxidative stress [5]. These ingredients are considered to protect neuronal cells mainly via the reduction of ROS. It is worthwhile to study different patterns of nutrition and their role in preventing oxidative stress. Since oxidative damage of cells increases with age, the increased intake of exogenous antioxidants may support the endogenous antioxidative defense. Clinical studies imply that eating certain foods (such as fruits, vegetables, whole grains, products rich in omega-3 fatty acids) can help humans in decreasing oxidative stress and postponing the incidence of degenerative diseases [6]. It is of interest to study the antioxidant capacity of foods with regular and daily consumption, because a better effect would be achieved. Bread is a staple food for the population in many countries around the world. Bread made with refined wheat flour is a food with a low antioxidant capacity [8]. Therefore, enriching bread with antioxidant substances would reduce oxidative stress and improve the health status of the population as a whole.

In the last decade, many studies have demonstrated that the consumption of food enriched in antioxidants and bioactive compounds, able to counteract oxidative stress, may represent a strategic tool to maintain health and wellness and to prevent disease caused by oxidative stress [7]. Due to the huge variety of products containing natural antioxidants, it is of interest to study the optimal amounts for their use in wheat bread formulation and their effect on its antioxidant capacity. Many algae have been demonstrated to have antioxidant properties, but few studies have investigated the antioxidant activity of bread supplemented with them. In addition, little information is available regarding the relationships between the active compounds and antioxidant activities in bread made with algae.

The influence of brown algae on the antioxidant properties when added directly into gluten-free bread (GFB) recipe was determined by Różyło et al. [9]. Algae powder was added in the quantity of $2,4,6,8$, and $10 \%$ of the total flour content. Brown algae addition significantly increased the antioxidant activity of GFB. Most importantly, antiradical compounds from the functional products were highly bio accessible in vitro. The results confirm the possibility of the use of brown algae powder in the production of GFB. It has not been studied how this brown seaweed (Kelp) would affect the antioxidant capacity of glutencontaining wheat bread.

The antioxidant properties of another kind of algae - Spirulina platensis, are attributed to molecules such as phycocyanin, $\beta$-carotene, tocopherol, $\gamma$-linolenic acid and phenolic compounds [10]. Phycocyanin is a water-soluble pigment and the major antioxidant compound in Spirulina [11]. The antioxidant properties of phycocyanin of Spirulina platensis are related to its radical scavenging and metal chelating activities [12]. It is of interest to study the effect of Spirulina platensis, added in various amounts, on the antioxidant capacity of wheat bread. 
Brown algae Kelp and blue-green algae Spirulina platensis contain numerous biologically active substances with a proven positive effect on human health. In many countries, a modern trend is the enrichment of various foods with these two types of algae. It is worthwhile to investigate the effect of these two types of algae added in different amounts to the wheat bread recipe, on its antioxidant capacity.

The aim of the research is to study the effect of Spirulina platensis and Kelp (added in the amount of $2 \%$ and $4 \%$ ) on antioxidant activity of wheat bread.

\section{Materials and methods}

\section{Materials}

For the preparation of the bread samples, the following materials were used:

- Commercial wheat flour type 500 with the following properties: moisture content $12.8 \%$; gluten content $-27.07 \%$; release of gluten $-6 \mathrm{~mm}$; titratable acidity $-2{ }^{\circ} \mathrm{H}$;

- Water - according to ISO 6107-1:2004;

- Commercial yeast (Lesafmaya);

- Salt - according to Codex Standard for Food Grade Salt CX STAN 150-1985;

- Spirulina platensis powder (average chemical composition: protein $64 \mathrm{~g} / 100 \mathrm{~g}$; fat 8.2 $\mathrm{g} / 100 \mathrm{~g}$ of which saturated $3.42 \mathrm{~g}$; carbohydrates $16.1 \mathrm{~g} / 100 \mathrm{~g}$, of which sugars $0.52 \mathrm{~g}$, fiber $7 \mathrm{~g} / 100 \mathrm{~g})$.

- Kelp powder (average chemical composition: protein $5.3 \mathrm{~g} / 100 \mathrm{~g}$; fat $4.2 \mathrm{~g} / 100 \mathrm{~g}$ of which saturated $0.9 \mathrm{~g}$; carbohydrates $12.0 \mathrm{~g} / 100 \mathrm{~g}$, of which sugars $0.5 \mathrm{~g}$, fiber 1.25 $\mathrm{g} / 100 \mathrm{~g})$.

\section{Methods}

\section{Dough and bread composition}

The composition of the bread samples is presented in Table 1.

Bread samples composition

Table 1

\begin{tabular}{|l|c|c|c|c|c|}
\hline & \multicolumn{5}{|c|}{ Bread samples } \\
\cline { 2 - 6 } Ingredients & $\begin{array}{c}\text { Control } \\
\text { sample }\end{array}$ & $\begin{array}{c}\text { Sample } \\
\text { with 2\% } \\
\text { Spirulina } \\
\text { platensis (S2) }\end{array}$ & $\begin{array}{c}\text { Sample } \\
\text { with 4\% } \\
\text { Spirulina } \\
\text { platensis (S4) }\end{array}$ & $\begin{array}{c}\text { Sample } \\
\text { with 2\% } \\
\text { Kelp } \\
(\mathbf{K 2})\end{array}$ & $\begin{array}{c}\text { Sample } \\
\text { with 4\% } \\
\text { Kelp } \\
\text { (K4) }\end{array}$ \\
\hline $\begin{array}{l}\text { Wheat flour } \\
\text { (type 500), g }\end{array}$ & 250 & 245 & 240 & 245 & 240 \\
\hline Water, cm ${ }^{3}$ & 140 & 145 & 155 & 145 & 155 \\
\hline Yeast, g & 3.37 & 3.37 & 3.37 & 3.37 & 3.37 \\
\hline Salt, g & 3.25 & 3.25 & 3.25 & 3.25 & 3.25 \\
\hline $\begin{array}{l}\text { Spirulina } \\
\text { platensis, g }\end{array}$ & - & 5 & 10 & - & - \\
\hline Kelp, g & - & - & - & 5 & 10 \\
\hline
\end{tabular}




\section{Bread preparation}

Bread is obtained from type 500 wheat flour by a two-phase method. Initially, knead the yeast, flour and water dough in a 1:1 ratio in kneading machine (Labomix 1000, Hungary). Pre-mixed Spirulina platensis and Kelp algae (powder) in the amount of $2 \%$ or $4 \%$ by the weight of flour are added to the mixing water. (combinations $\mathrm{K} 2$ and $\mathrm{K} 4$, for the breads prepared with Kelp and combinations S2 and S4, for the breads prepared with Spirulina platensis, respectively). The control sample was prepared only with wheat flour. The dough thus prepared matures for 4 hours at $33^{\circ} \mathrm{C}$ and then mix the dough to obtain a homogeneous mass by adding the remainder of the flour to the formulation and salt $(1.3 \mathrm{~kg} / 100 \mathrm{~kg}$ flour). The bread dough divides $\left(440 \mathrm{~g}\right.$ ) and forms, matures for 55 minutes at $38^{\circ} \mathrm{C}$ (Tecnopast CRN 45-12, Novacel ROVIMPEX Novaledo, Italy). After the final fermentation, the pieces of dough were put into an electric oven (Salva E-25, Spain) pre-heated to $200-220{ }^{\circ} \mathrm{C}$. The baking time is $24 \mathrm{~min}$, until the temperature in the center of the bread crumb reach $96-98{ }^{\circ} \mathrm{C}$. After baking, the bread is allowed to cool down for $3 \mathrm{~h}$ at room temperature.

\section{Sample extraction}

The extraction process of bioactive compounds from dry breads was carried out with 70\% ethanol as described in Vasileva et al., 2018 [13]. Bread samples were sliced (about 1.5 $\mathrm{cm}$ thick), dried $\left(40{ }^{\circ} \mathrm{C}, 24 \mathrm{~h}\right)$, ground in a mill, and sieved ( $0.5 \mathrm{~mm}$ sieve). Ethanol extracts from breads were obtained with 70\% ethanol (solid to liquid ratio 1:20) in an ultrasonic bath (VWR, Malaysia; $45 \mathrm{kHz}, 30 \mathrm{~W}$ ) at $45^{\circ} \mathrm{C}$ for $15 \mathrm{~min}$. Samples were then centrifuged at $1800 \mathrm{xg}$ for $15 \mathrm{~min}$ (MPW-251, Med. Instruments, Poland). The supernatants were used for further studies.

\section{Analytical methods}

a. Total polyphenols were quantified by using Folin-Ciocalteu's reagent (Ainsworth and Gillespie, 2007) [14]. Gallic acid was employed as calibration standard and the results were expressed as mg equivalents gallic acid (GAE) per gram dry weight (DW).

b. Total flavonoids were determined using $\mathrm{Al}\left(\mathrm{NO}_{3}\right)_{3}$ reagent and measuring the absorbance at $415 \mathrm{~nm}$ according to Kivrak et al., 2019 [15]. The results were expressed as mg equivalents quercetin $(\mathrm{QE})$ per gram $\mathrm{DW}$.

\section{c. In vitro antioxidant activity determination}

The antioxidant activity of ethanolic extracts was evaluated by three methods: FRAP (ferric reducing antioxidant power), DPPH (2,2-diphenyl-1-picrylhydrazyl) radical scavenging method and hydroxyl radical $(\mathrm{OH} \cdot)$ scavenging assay (HRSA).

\section{FRAP (Ferric Reducing Antioxidant Power) method}

The FRAP method is based only on single electron transfer mechanism and was measured according to the method of Dimov et al. [16] with some modification. Three $\mathrm{ml}$ freshly prepared FRAP reagent (10 parts $0.3 \mathrm{M}$ acetate buffer ( $\mathrm{pH} 3.6$ ), 1 part $10 \mathrm{mM} \mathrm{2,4,6-}$ tripyridyl-s-triazine (TPTZ) in $40 \mathrm{mM} \mathrm{HCl}$ and 1 part $20 \mathrm{mM} \mathrm{FeCl} 3.6 \mathrm{H} 2 \mathrm{O}$ in $\mathrm{d} . \mathrm{H}_{2} \mathrm{O}$ ) were mixed with $0.1 \mathrm{ml}$ of investigated ethanolic extract. The reaction time was 10 min at $37{ }^{\circ} \mathrm{C}$ in darkness and the absorbance was measured at $593 \mathrm{~nm}$ against blank prepared with $70 \%$ ethanol. A standard curve was built with $\mathrm{FeSO}_{4} \cdot 7 \mathrm{H}_{2} \mathrm{O}$. The results of FRAP analysis were expressed as $\mu \mathrm{mol} \mathrm{Fe}{ }^{2+}$ equivalents per gram DW (Irshad et al., 2012) [17]. 


\section{DPPH radical scavenging assay}

The DPPH radical method is based on mixed hydrogen atom transfer and single electron transfer mechanisms.

DPPH radical scavenging activity was estimated according to Dimov et al., 2018 [16] with some modification. Briefly, $0.15 \mathrm{ml}$ of ethanolic extract was mixed with $2.85 \mathrm{ml} 0.06$ $\mathrm{mM}$ DPPH fresh solution in 96\% ethanol. The mixture was left for $30 \mathrm{~min}$ (kept in the dark at room temperature) so that a reaction could take place, and then the absorbance at $517 \mathrm{~nm}$ was read by spectrophotometer in comparison to the blank containing $70 \%$ ethanol. The results of DPPH analysis were expressed as mmol Trolox equivalents (TE) per gram DW.

\section{Hydroxyl radical scavenging assay (HRSA)}

The scavenging activity for hydroxyl radicals was measured with Fenton reaction with a few modifications (Jin et al., 1996) [18]. OH. could oxidize $\mathrm{Fe}^{2+}$ into $\mathrm{Fe}^{3+}$, and only $\mathrm{Fe}^{2+}$ could combine with 1,10-phenanthroline to form a red colored complex with the maximum absorbance at $536 \mathrm{~nm}$. The concentration of hydroxyl radical was determined by the degree of decolourization of the reaction solution. The reaction mixture contained $1 \mathrm{ml}$ of $0.75 \mathrm{mM}$ 1,10-phenanthroline, $2 \mathrm{ml}$ of $0.2 \mathrm{M}$ phosphate buffer $(\mathrm{pH}=7.4), 1 \mathrm{ml}$ of $0.75 \mathrm{mM}$ FeSO4. $7 \mathrm{H}_{2} \mathrm{O}, 1 \mathrm{ml} \mathrm{H}_{2} \mathrm{O}_{2}(0.01 \% \mathrm{v} / \mathrm{v})$, and $1 \mathrm{ml}$ of investigated ethanolic extract was incubated at $37^{\circ}$ for $60 \mathrm{~min}$ in a water bath. The absorbance of reaction mixture was measured at $536 \mathrm{~nm}$ against reagent blank. The results of HRSA were expressed as $\mu \mathrm{g}$ BHT (3,5-Ditert-4-butylhydroxytoluene) per gram DW.

\section{Statistical analysis}

Results are presented as means of at least three independent determinations \pm standard deviation (SD). Statistical evaluation was performed by using one-way analysis of variance (ANOVA) of the IBM SPSS Statistics program (Somers, NY, USA). Mean differences were established by Fisher's least significant difference test for paired comparison with a significance level $\alpha=0.05$.

\section{Results and discussion}

\section{Determination of total polyphenol and flavonoid contents}

Due to the variety of bioactive compounds contained in algae and their differing solubility properties in different solvents, the optimal solvent for extraction depends on the particular algae materials, and the compounds that are to be isolated [19,20]. According to Poole et al. [21], 75\% ethanol aqueous solution, nearly doubled the polyphenol yield when compared to extraction with water alone. Based on this background and many other reports, in the present study, we employed extraction of bioactive compounds from the breads using ultrasound and $70 \%$ ethanol as a good extraction solvent. We evaluated the in vitro antioxidant properties of the 70\% ethanol extracts and correlated their antioxidant activities with 2,2-diphenyl-1-picrylhydrazyl (DPPH method), ferric reducing antioxidant power (FRAP method) and hydroxyl radical scavenging activities (HRSA). In addition, we determined the total polyphenol and flavonoid contents in the different types of bread, i.e. phenolic compounds are considered to be dominant contributors to the antioxidant activity and also possess many biological activities. 
Polyphenols serve as powerful antioxidants due to the hydrogen-donating ability of their hydroxyl groups as well as their ability to donate electrons to arrest the production of free radicals as a result of oxidative stress [22]. Flavonoids are the largest class of polyphenols.

The total polyphenol and flavonoid contents of ethanol extracts from bread samples prepared with $2 \%$ and $4 \%$ Kelp (K2 and K4), and $2 \%$ and $4 \%$ Spirulina platensis (S2 and S4) are presented in Table 2.

\section{Comparison of total polyphenol and flavonoid contents in ethanol extracts}

Table 2

\begin{tabular}{|c|c|c|}
\hline Ethanol extracts & $\begin{array}{c}\text { Total polyphenol, } \\
\text { mg GAE/g DW }\end{array}$ & $\begin{array}{c}\text { Total flavonoids, } \\
\text { mg QE/g DW }\end{array}$ \\
\hline Control & $0.68 \pm 0.01^{\mathrm{c}}$ & $0.13 \pm 0.00^{\mathrm{c}}$ \\
\hline K2 & $0.52 \pm 0.03^{\mathrm{d}}$ & $0.11 \pm 0.00^{\mathrm{d}}$ \\
\hline K4 & $0.44 \pm 0.05^{\mathrm{e}}$ & $0.10 \pm 0.00^{\mathrm{e}}$ \\
\hline S2 & $0.74 \pm 0.01^{\mathrm{b}}$ & $0.20 \pm 0.00^{\mathrm{b}}$ \\
\hline S4 & $0.88 \pm 0.02^{\mathrm{a}}$ & $0.28 \pm 0.00^{\mathrm{a}}$ \\
\hline
\end{tabular}

Note: DW - dry weight bread.

The results were expressed as mean $\pm \mathrm{SD}(\mathrm{n}=3)$.

a-e Means in a column with different superscripts differ significantly $(\mathrm{p}<0.05)$.

Significant differences in total polyphenol content were found among different quantities of Kelp and Spirulina platensis added in breads. The addition of S. platensis (2 and 4\%), compared to the control sample generally increased the polyphenol content in breads. The highest polyphenols content had S4: $0.88 \pm 0.02 \mathrm{mg} \mathrm{GAE} / \mathrm{g} \mathrm{DW}$. The difference between the values of the control sample and samples S2 and S4 expressed as percentage increase were $9 \%$ and $29 \%$, respectively. Cozmuta et al. [23] reported similar results for higher level of polyphenols in the bread enriched with Spirulina powder. By increasing the amount of incorporated Spirulina with $1 \%, 3 \%$ and 5\%, the polyphenols content rises 1.19-fold, 1.41fold and 2.73-fold, compared to control bread. Increased polyphenols content of breads was also observed by Saharan and Jood [24], while investigating antioxidant activity of bread enriched with 2, 4 and $6 \%$ S. platensis powder.

A reduction in the polyphenol content with the increase of the quantity of $\operatorname{Kelp}(2 \%$ and $4 \%$ ) added in bread was observed, compared to control sample. The lowest level in the polyphenols content had K4: 0.44 $\pm 0.05 \mathrm{mg}$ GAE/g DW. The difference between the values of the control sample and samples $\mathrm{K} 2$ and $\mathrm{K} 4$ expressed as percentage reduction were $24 \%$ and $35 \%$, respectively.

The same order of total flavonoids was obtained. Total flavonoids of control sample were: $0.13 \mathrm{mg} \mathrm{QE} / \mathrm{g} \mathrm{DW}$ (19\% of the content of the total polyphenols), K2 - $0.11 \mathrm{mg}$ QE/g DW ( $21 \%$ of the content of the total polyphenols), K4 $-0.10 \mathrm{mg} \mathrm{QE} / \mathrm{g}$ DW (23\% of the content of the total polyphenols), S2 $-0.20 \mathrm{mg} \mathrm{QE} / \mathrm{g} \mathrm{DW}$ (27\% of the content of the total polyphenols), $\mathrm{S} 4-0.28 \mathrm{mg} \mathrm{QE} / \mathrm{g} \mathrm{DW}$ (32\% of the content of the total polyphenols). Overall, the total polyphenols and flavonoids were in the order $\mathrm{S} 4>\mathrm{S} 2>\mathrm{Control}$ sample>K2>K4.

Seghiri et al. [25] used absolute methanol for extraction of polyphenols and flavonoids from $S$. platensis biomass and reported very low yield of polyphenols $-0.29 \mathrm{mg} \mathrm{GAE} / \mathrm{g} \mathrm{DW}$. However, the amount of extracted flavonoids is higher than in our research $-58 \%$ of the content of the total polyphenols $(0.17 \mathrm{mg} \mathrm{QE} / \mathrm{g} \mathrm{DW})$. 


\section{Determination of antioxidant activity}

Antioxidant activity is a complex procedure usually happening through several mechanisms and is influenced by many factors, which cannot be fully described with one single method [26]. Therefore, it is essential to perform more than one type of antioxidant capacity measurement to take into account the various mechanisms of antioxidant action [27 - 29]. In this study, the antioxidant properties of ethanol extracts from breads prepared with Kelp and Spirulina platensis in different concentration (2 and 4\%) were determined by DPPH, FRAP, and hydroxyl radical scavenging assays (HRSA), and were compared with the control sample (made with white flour, $0 \%$ algae). Antioxidant potentials of the samples varied with species of algae and the quantity imported into flour.

DPPH assay is one of the most popular and frequently employed methods among antioxidant assays. The method is simple, efficient, relatively inexpensive, and quick [30]. The method is based on the reduction of DPPH, a stable free radical [31]. The free radical DPPH with an odd electron gives a maximum absorption at $517 \mathrm{~nm}$ (purple colour). When antioxidants react with DPPH, which is a stable free radical becomes paired off in the presence of a hydrogen donor (e.g., a free radical-scavenging antioxidant) and is reduced to the DPPHH and as consequence the absorbance's decreased from the DPPH [32]. Radical to the DPPH-H form, results in decolorization (yellow colour) with respect to the number of electrons captured [33]. More the decolorization more is the reducing ability [34].

The DPPH radical scavenging activity of the ethanol extracts is shown in Figure 1.

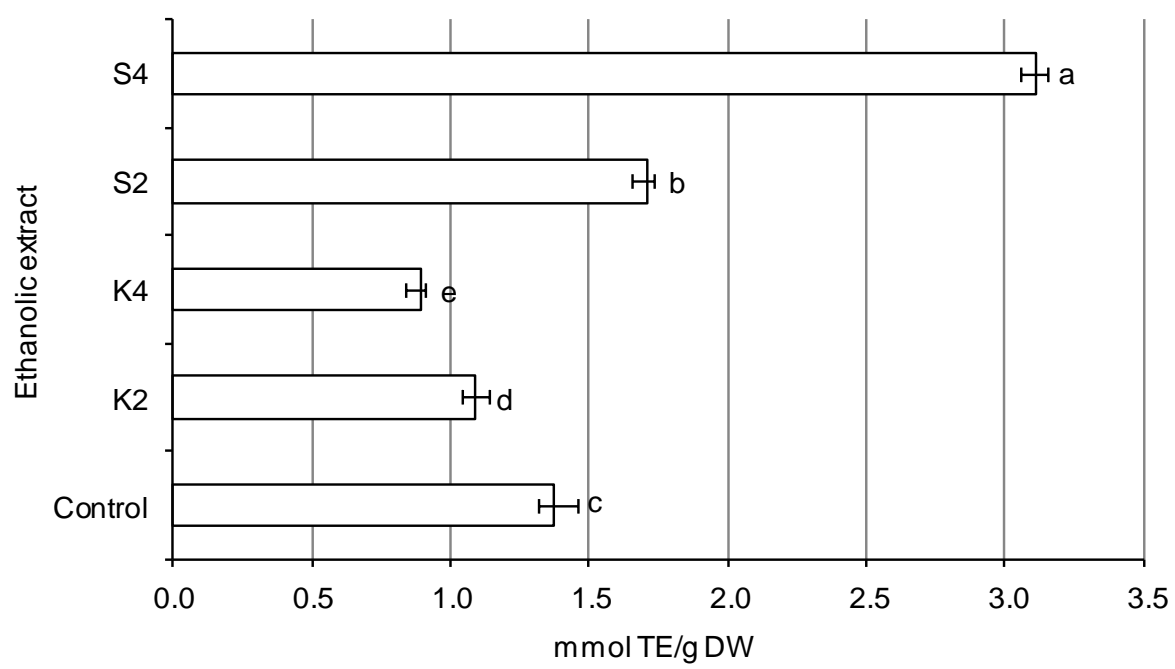

Figure 1. DPPH radical scavenging activity (mmol TE/g DW) of ethanol extracts

${ }^{a-e}$ Means with different lowercase letters differ significantly $(\mathrm{p}<0.05)$.

Note: DW - dry weight bread.

The results of our work indicate a correlation between DPPH radical scavenging activities and total polyphenol and flavonoid contents. The DPPH radical scavenging activity of S2 and S4 increased in a concentration-dependent manner, and the highest value was $3.11 \pm 0.05 \mathrm{mmol} \mathrm{TE} / \mathrm{g} \mathrm{DW}$ in S4, followed by S2 - 1.71 $\pm 0.03 \mathrm{mmol} \mathrm{TE} / \mathrm{g} \mathrm{DW}$. In contrast, the lowest DPPH scavenging capacities were observed in ethanol extracts received from bread with $4 \%$ Kelp $-\mathrm{K} 4(0.89 \pm 0.02 \mathrm{mmol}$ TE/g DW) and 2\% Kelp $-\mathrm{K} 2(1.09 \pm 0.05 \mathrm{mmol}$ 
TE/g DW). Both K2 and K4 had lower DPPH radical scavenging activity than the control sample $(1.37 \pm 0.09 \mathrm{mmol} \mathrm{TE} / \mathrm{g} \mathrm{DW})$, as that decrease is in a concentration-dependent manner, too. This can be explained by the baking at high temperature $\left(200-220{ }^{\circ} \mathrm{C}\right)$, which may destroy some bioactive compounds in Kelp algae and decrease the inhibition of DPPH radical scavenging activities.

Our results are in agreement with the findings of El Baky et al. [35] and Singh et al. [36], considering that the antioxidant capacity increases with the increasing levels of $S$. platensis in bread. Cozmuta et al. [23] reported similar results for higher antioxidant activity (by DPPH method), after the addition of $1 \%, 3 \%$ and $5 \%$ S. platensis in the bread. It increased to $11.06 \%$ in bread with $1 \%$ S. platensis, $13.21 \%$ in bread with $3 \%$ S. platensis and $15.46 \%$ in bread with $5 \%$ S. platensis from $10.24 \%$ in control bread.

The incorporation of $6 \%$ and $10 \%$ S. platensis in "crostini" led to a significant increase in DPPH radical scavenging capacity, compared to the control [37] sample.

Increased antioxidant capacity (by DPPH method) was also observed by Saharan and Jood [24], while investigating breads enriched with 2, 4 and $6 \% \mathrm{~S}$. platensis powder. Maximum antioxidant activity they observed in 6\% Spirulina supplemented bread.

Carp and barbel burgers containing $1 \%$ of Spirulina showed significantly higher DPPH scavenging activities (86.76\% and $94.09 \%$, respectively) than control burgers $(56.28 \%$ and 40.09\%) [38].

FRAP method. The method is based on the reduction of $\mathrm{Fe}^{3+}$ TPTZ complex (colorless complex) to $\mathrm{Fe}^{2+}$-tripyridyltriazine (blue colored complex) formed by the action of electron donating antioxidants at low $\mathrm{pH}$ [39]. The results of our work indicate a correlation between the reducing power determined by FRAP method, DPPH radical scavenging activity, and total polyphenol and flavonoid contents. Antioxidant ability of the ethanol extracts for reducing $\mathrm{Fe}^{3+}$ by the FRAP values reflecting the ranged from 2.77 to $5.04 \mu \mathrm{mol} \mathrm{Fe} \mathrm{F}^{2+} / \mathrm{g} \mathrm{DW}$ (Figure 2).

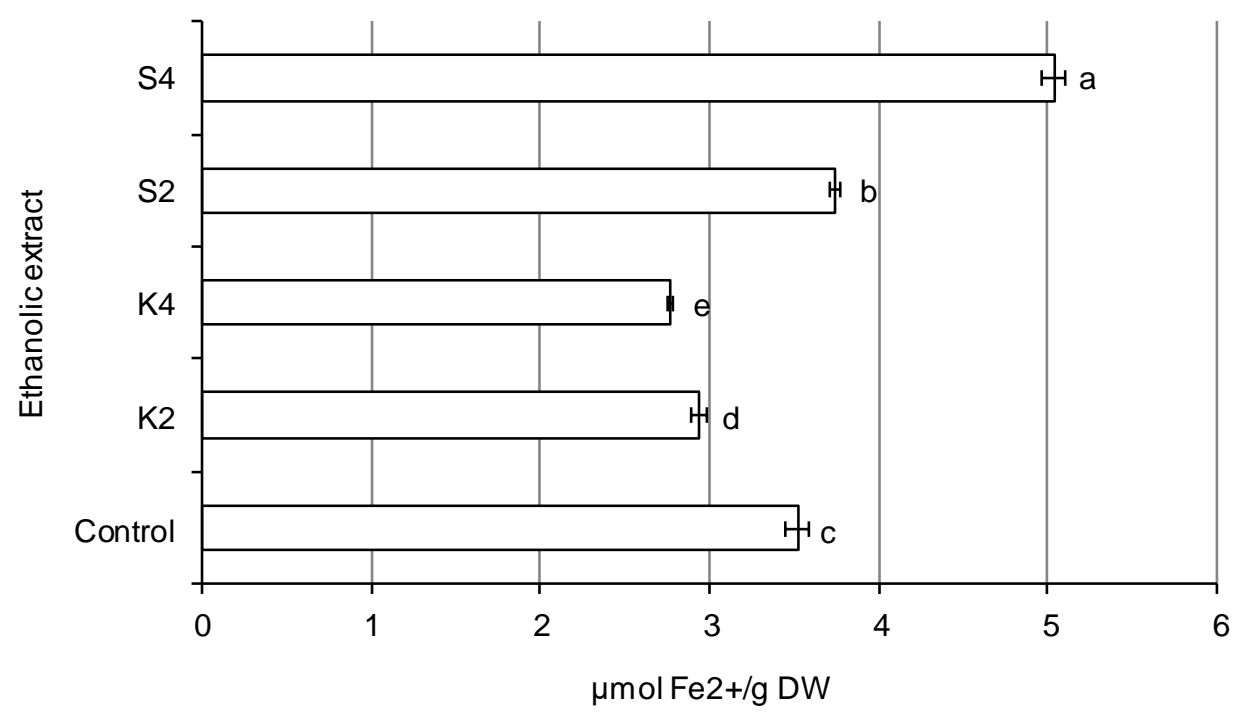

Figure 2. Ferric Reducing Antioxidant Power $\left(\mu \mathrm{mol} \mathrm{Fe} \mathrm{F}^{2+/} \mathrm{g} \mathrm{DW}\right)$ of ethanol extracts ${ }^{a-e}$ Means with different lowercase letters differ significantly $(\mathrm{p}<0.05)$.

Note: DW - dry weight bread. 
FRAP assays varied significantly among species. The sample S4 showed the highest mean FRAP $\left(5.04 \pm 0.07 \mu \mathrm{mol} \mathrm{Fe}{ }^{2+} / \mathrm{g}\right.$ DW), followed by S2 $\left(3.75 \pm 0.03 \mu \mathrm{mol} \mathrm{Fe}^{2+} / \mathrm{g} \mathrm{DW}\right)$, control sample $\left(3.52 \pm 0.07 \mu \mathrm{mol} \mathrm{Fe} \mathrm{Fe}^{2+} / \mathrm{g} \mathrm{DW}\right), \mathrm{K} 2\left(2.94 \pm 0.04 \mu \mathrm{mol} \mathrm{Fe} \mathrm{Fe}^{2+} / \mathrm{g} \mathrm{DW}\right)$ and K4 $\left(2.77 \pm 0.02 \mu \mathrm{mol} \mathrm{Fe}{ }^{2+} / \mathrm{g} \mathrm{DW}\right)$. Our results contradict the results of another team of authors [40], and according to them brown algae E. arborea had higher FRAP value $(11.9 \mu \mathrm{mol}$ $\left.\mathrm{FeSO}_{4} \mu \mathrm{g}^{-1}\right)$ than the red A. spicifera $\left(9.8 \mu \mathrm{mol} \mathrm{FeSO} \mu_{4} \mathrm{~g}^{-1}\right)$, and the green $R$. intrincata had the lowest FRAP value mean $\left(2.6 \mu \mathrm{mol} \mathrm{FeSO} 4 \mu^{-1}\right)$.

The reducing power of the ethanol extracts from Spirulina-containing breads may serve as a significant indicator of its potential antioxidant activity. This activity may be due to phenolic compounds and flavonoids present in the extract as also indicated by Velioglu et al. [41].

Carp and barbel burgers containing $1 \%$ of Spirulina showed significantly higher ferric reducing activity ( 0.615 and 0.584 is absorbance at $700 \mathrm{~nm}$, respectively) than control burgers (0.315 and 0.410 is absorbance at $700 \mathrm{~nm})$ [42] as in our work with Spirulina-breads.

Hydroxyl radical scavenging assay (HRSA). The hydroxyl radical is the most reactive free radical and can be formed from superoxide anions and hydrogen peroxides in the presence of metal ions, such as copper and iron. Hydroxyl radicals can cause damage to nearly all types of biomolecules, including proteins, DNA, polyunsaturated fatty acids, and nucleic acids [43]. The scavenging effect of $\mathrm{OH}$ was investigated using the Fenton reaction and the results are shown in Figure 3.

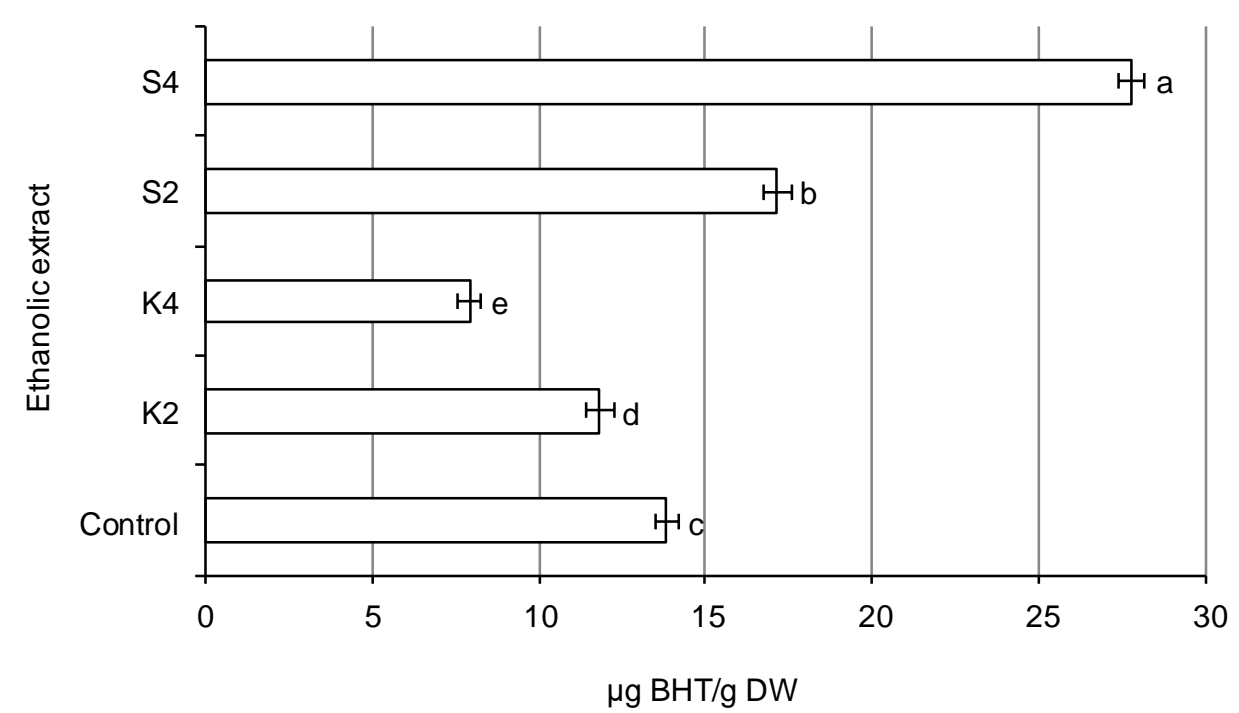

Figure 3. Hydroxyl radical scavenging activity ( $\mu \mathrm{g}$ BHT/g DW) of ethanol extracts $\mathrm{a}-\mathrm{e}$ Means with different lowercase letters differ significantly $(\mathrm{p}<0.05)$.

Note: DW - dry weight bread.

With an increased content of $S$. platensis concentration, significant changes were noted in the Hydroxyl radical scavenging activity. The highest values were $27.8 \pm 0.4 \mu \mathrm{g} B \mathrm{HT} / \mathrm{g}$ DW in S4, and 17.16 $\pm 0.42 \mu \mathrm{g} \mathrm{BHT/g} \mathrm{DW} \mathrm{in} \mathrm{S2.} \mathrm{Singh} \mathrm{et} \mathrm{al.} \mathrm{[36]} \mathrm{found} \mathrm{a} \mathrm{linear} \mathrm{positive}$ 
correlation between S. platensis concentration (from 1.6 to $8.4 \%$ ) in biscuits and antioxidant activity. The control sample showed the same trend $(13.85 \pm 0.37 \mu \mathrm{g}$ BHT/g DW) - higher value than K2 (11.85 $\pm 0.42 \mu \mathrm{g}$ BHT/g DW) and K4 (7.94 $\pm 0.34 \mu \mathrm{g}$ BHT/g DW), as with other two methods for determining the antioxidant activity. The results of our work indicate a correlation between Hydroxyl radical scavenging activity, the reducing power determined by FRAP method, DPPH radical scavenging activity, and total polyphenol and flavonoid contents.

\section{Discussion}

The use of S. platensis in the food industry has been reported by many authors. Spirulina can be supplemented to noodles, breads, biscuits, candies, ice cream, bean curd etc. as food additives to enhance nutritive and health values [44]. Spirulina extracts are used to enrich liquid foods such as health drink, soft drink, tea, beer or spirits [21]. Powder can be used in a variety of food products like soups, sauces, pasta, snack foods, instant drinks and other recipes. Extraction methods can be used to obtain discoloured Spirulina powder (yellowwhite) which is odorless and tasteless, and thus suitable for widespread use [45]. Herero et al. [46] recommended that ethanol rather than other solvents should be used for the extraction of antioxidants from Spirulina, as it is regarded as Generally Recognized as Safe (GRAS), if the extracts are to be used as a functional ingredient in the food industry.

According to Omidi et al. [47], Spirulina-containing pasta had a higher phenolic content and an antioxidant activity than the control pasta. El Baky et al. [35] observed increasing antioxidant activity for biscuits containing S. platensis biomass (from 0.3 to $0.9 \%$ ). Bolanho et al. [48] reported that the addition of 5\% S. platensis to formulations of cookies increase content of protein, fiber, ash, total phenolic compounds and antioxidant capacity. They showed an increase of about $65 \%$ (from 1.4 to $2.3 \mathrm{mg} \mathrm{GAE} \mathrm{g}^{-1}$ ) in total phenolic content in $5 \%$ S. platensis cookies when compared to the control sample. Barkallah et al. [38] tested the addition of $1 \%$ Spirulina in carp and barbel burgers and found a significant increase in their antioxidant activities, compared to the control burgers.

Many studies have demonstrated high antioxidant potential of brown seaweed [49-52]. The bioactive properties are mainly due to the presence of phlorotannin [53], a type of polyphenol (secondary metabolite) [54]. Ascophyllum nodosum (Kelp) is one of the brown algae species with the highest concentrations of phlorotannin (9-14\% of its dry weight, depending on seasonal variability) [55]. Phlorotannins have received increasing interest because of their antioxidant, anti-wrinkling, antiallergic, anti-cancer, and hair growthpromoting abilities [56-58]. These characteristics make brown seaweed a useful and valuable ingredient for functional foods [59].

Research on bakery products with brown algae is scarce. The only study focused on the antioxidant activity of bread supplemented with brown algae was published by Rózylo et al. [9]. According to them, the addition of brown algae in bread leads to significant increase in bioactive properties. But, the results obtained by us for the polyphenol and flavonoid contents, and antioxidant activity of the ethanolic extracts from breads prepared with two Kelp concentrations ( $2 \%$ and $4 \%$ ) were unexpected.

This could be partially explained by the phlorotannin concentration. It reacts to the algae's external conditions, such as light, temperature, and biotic stressors, as well as sample handling and preservation methods [21]. Studies have shown that phenolic concentration monitored over a year in one brown algae species found that yields differed seasonally [60].

According to Poole et al. [26], lower phenolic content is the result of sun exposure likely causes a degradation of phlorotannins. Cruces et al. [61] and Esteban et al. [62] made similar 
conclusion. They observed that drying processes that require longer time lengths to dehydrate the seaweed samples tended to have a loss in phlorotannins and antioxidant capacity due to degradation and oxidation. These suggestions likely explain why the breads prepared with Kelp have lower bioactivity, compared to control sample.

According to Mekini'c et al. [63], the solubility of the bioactive compounds is governed by the type of solvent used, degree of polymerization and their interactions with other food constituents what leads to formation of insoluble complexes.

According to Velioğlu et al. [41], different baking processes used to produce different products (breads, cookies and cakes, contained equal amount of hazelnut testa in the formulation), significantly affect the amount of phenolics.

On the other hand, polyphenols content varies depending on the efficiency of the extraction method [21]. For example, some compounds, such as water-soluble polysaccharides, protein and organic acids are simultaneously extracted when using water alone as the extraction solvent [65]. Lopez et al. [66] compared the phenolic contents and antioxidant activity of the water, water/methanol (1/1), methanol and ethanol extracts from the brown seaweed Stypocaulon scoparium and found that the aqueous extracts showed the highest phenolic content and antioxidant activity. So that, used to our work $70 \%$ ethanol may not be sufficiently effective to extract bioactive components of bread made with Kelp.

\section{Conclusion}

Ethanol extracts from breads prepared with Spirulina platensis exhibited high antioxidant activity. The bread prepared with 4\% Spirulina platensis showed the highest content of the phenolic compounds and antioxidant activity with all the methods used. With an increased content of brown algae, significant changes were noted down in the content of the phenolic compounds and antioxidant activities. Their values decreased significantly with increasing brawn algae addition (in the range of 2-4\%). There is a positive correlation between total polyphenol and flavonoid contents, and the antioxidant activity determined by FRAP method, DPPH method, and Hydroxyl radical scavenging assay. This correlation indicates that the phenolic compounds largely contribute to the antioxidant activities of these algal species.

Acknowledgements. Authors would like to thank to the Ministry of Education
and Science of Bulgaria about the subsidy by Regulation № 3 from 27.11 .2015
- in accordance with the Ordinance on the Terms and Procedure for the
Evaluation, Planning, Allocation and Expenses of the State Budget Funds for
the Financing of the Inherent Research Activities of the State Higher Education
Institutions. The acknowledgements are also to the academic management of
University of Economics - Varna for the allocations in project NPI-16/2018
"Innovative approaches to increase the quality and biological value of foods".

\section{References}

1. Ray P., Huang B., Tsuji Y. (2012), Reactive oxygen species (ROS) homeostasis and redox regulation in cellular signaling, Cellular Signaling, 24, pp. 981-990. 


\section{— Food Technology —}

2. Poljsak B., Fink R. (2014), The protective role of antioxidants in the defence against ROS/RNS-mediated environmental pollution, Oxiative Medicine and Cellular Longevity, pp. 1-22.

3. Dalle-Donne I., Rossi R., Colombo R., Giustarini D., Milzani A. (2006), Biomarkers of oxidative damage in human disease, Clinical Chemistry, 52(4), pp. 601-623.

4. Dhalla N. S., Temsah R. M., Netticadan T. (2000), Role of oxidative stress in cardiovascular diseases, Journal of Hypertension, 18(6), pp. 655-673.

5. Spagnuolo M., Napolitano I., Tedesco S., Moccia A., Milito G., Russo L. (2016), Neuroprotective role of natural polyphenols, Current Topics in Medicinal Chemistry, 16, pp. 1943-1950.

6. Willett W. (2006), The Mediterranean diet: science and practice, Public Health Nutrition, 9(1), pp. 105-110.

7. Giampieri F., Forbes-Hernandez T., Gasparrini M., Afrin S., Cianciosi D., ReboredoRodriguez P., Varela-Lopez A., Quiles J., Mezzetti B., Battino M. (2017), The health effects of strawberry bioactive compounds on molecular pathways related to chronic diseases, Annals of The New York Academy of Sciences, 398, pp. 62-71.

8. Gunenc A., Tavakoli H., Seetharaman K., Mayer P. M., Fairbanks D., Hosseinian F. (2013), Stability and antioxidant activity of alkyresorcinols in breads enriched with hard and soft wheat brans, Food Research International, 51, pp. 571-578.

9. Różyło R., Hassoon W., Gawlik-Dziki U., Siastała M., Dziki D. (2017), Study on the physical and antioxidant properties of gluten-free bread with brown algae, Journal of Food, 15(2), pp. 196-203.

10. Chopra K. and Bishnoi M. (2008), Antioxidant profile of Spirulina: a blue-green microalga. In: Gershwin, M. E. and Belay, A. (Eds) Spirulina in Human Nutrition and Health (Boca Raton: CRC Press), pp. 101-118.

11. Chu W. L., Phang S. M., Miyakawa K., Tosu T. (2002), Influence of irradiance and inoculum density on the pigmentation of Spirulina platensis. Asia Pacific Journal of Molecular Biology and Biotechnology, 10(2), pp. 109-117.

12. Bermejo P., Pinero E., Villar A. M. (2008), Iron-chelating ability and antioxidant properties of phycocyanin isolated from a protean extract of Spirulina platensis, Food Chemistry, 110, pp. 436-445.

13. Vasileva, I., Denkova, R., Chochkov, R., Teneva, D., Denkova, Z., Dessev, Tz., Denev, P., Slavov, A. (2018), Effect of lavender (Lavandula angustifolia) and melissa (Melissa Officinalis) waste on quality and shelf life of bread, Food Chemistry, 253, p. 13-21.

14. Ainsworth, E. A., Gillespie K. M. (2007), Estimation of total phenolic content and other oxidation substrates in plant tissues using Folin-Ciocalteu reagent, Nat. Prot. 2, pp. 875877.

15. Kivrak, Ş, Göktürk T., Kivrak I., Kaya E., Karababa E. (2019), Investigation of phenolic profiles and antioxidant activities of some Salvia species commonly grown in Southwest Anatolia using UPLC-ESI-MS/MS, Food Sci. Technol., Campinas, 39(2), pp. 423-431.

16. Dimov I., Petkova N., Nakov G., Taneva I., Ivanov I., Stamatovska V. (2018), Improvement of antioxidant potential of wheat flours and breads by addition of medicinal plants, Ukrainian Food Journal, 7(4), pp. 671-681.

17. Irshad Md., Zafaryab Md., Singh M., Moshahid M. A. R. (2012), Comparative Analysis of the Antioxidant Activity of Cassia Fistula Extracts. Hindawi Publishing Corporation, International Journal of Medicinal Chemistry, Article ID 157125, DOI: $10.1155 / 2012 / 157125$.

18. Jin M., Cai Y. X., Li J. H., Zhao H. (1996), 1, 10-Phenanthroline- Fe2+ oxidative assay of hydroxyl radical produced by $\mathrm{H} 2 \mathrm{O} 2 / \mathrm{Fe} 2+$, Prog. Biochem. Biophys, 23, p. 553-555. 
19. Mahdi-Pour B., Jothy S. L., Latha L. Y., Chen Y., Sasidharan S. (2012), Antioxidant activity of methanol extracts of different parts of Lantana camara, Asian Pacific Journal of Tropical Biomedicine, 2(12), pp. 960-965.

20. Holdt S.L., Kraan S. (2011), Bioactive compounds in seaweed: Functional food applications and legislation, Journal of Applied Phycology, 23, pp. 543-597.

21. Poole J., Diop A., Rainville L. C., Barnabe S. (2019), Bioextracting Polyphenols from the Brown Seaweed Ascophyllum nodosum from Que'bec's North Shore Coastline, Industrial Biotechnology, 15(3), pp. 212-218.

22. Schmitt-Schillig S., Schaffer S., Weber C., Eckert G., Muller W. (2005), Flavonoids and the aging brain, Journal of physiology and pharmacology: an official journal of the Polish Physiological Society, 56(1), pp. 23-36.

23. Cozmuta A. M., Peter A., Nicula C., Cozmuta L. M. (2019), Impact of algae addition on bread properties and consumers' behavior-preliminary research, Carpathian Journal of Food Science and Technology, 11(1), pp. 121-125.

24. Saharan V. and Jood S. (2017), Vitamins, minerals, protein digestibility and antioxidant activity of bread enriched with Spirulina platensis powder, International Journal of Agriculture Sciences, 9(9), pp. 3917-3919.

25. Seghiri R., Kharbach M., Essamr A. (2019), Functional composition, nutritional properties, and biological activities of Moroccan Spirulina Microalga, Journal of Food Quality, 2019, pp. 1-11.

26. El Jemli M., Kamal R., Marmouzi I., Zerrouki A., Cherrah Y., Alaoui K. (2016), Radical-Scavenging Activity and Ferric Reducing Ability of Juniperus thurifera (L.), J. oxycedrus (L.), J. phoenicea (L.) and Tetraclinis articulate (L.), Hindawi Publishing Corporation, Advances in Pharmacological Sciences, 2016, pp. 1-6.

27. Schlesier K., Harwat M., B ohm V., Bitsch R. (2002), Assessment of antioxidant activity by using different in vitro methods, Free Radical Research, 36(2), pp. 177-187.

28. Aruoma O.I. (2003), Methodological considerations for characterizing potential antioxidant actions of bioactive components in plant foods, Mutation ResearchFundamental and Molecular Mechanisms of Mutagenesis, 523-524, pp. 9-20.

29. Wong S.P., Leong L.P., Koh J.H.W. (2006), Antioxidant activities of aqueous extracts of selected plants, Food Chemistry, 99(4), pp. 775-783.

30. Akar Z., Küçük M., Doğan H. (2017), A new colorimetric DPPH scavenging activity method with no need for a spectrophotometer applied on synthetic and natural antioxidants and medicinal herbs, Journal of Enzyme Inhibition and Medicinal Chemistry, 32(1), pp. 640-647.

31. Warrier P. K, Nambier V. P. K., Ramankutty C. (1994), Indian medicinal plants- A compendium of 500 species, Orient longman Ltd, Madras, 1, pp. 95-97.

32. Harborne J.B. (1998), Phytochemical methods - A guide to modern techniques of plant analysis, 3rd Edn., Springer (India) Pvt. Ltd, New Delhi, pp. 5-32.

33. Ghosh M. N. (1998), Fundamentals of Experimental Pharmacology, 2nd Edn., Scientific Book Agency (Calcutta), pp. 174-179.

34. Shekhar T. C. and Anju G. (2014), Antioxidant Activity by DPPH Radical Scavenging Method of Ageratum conyzoides Linn, Leaves, American Journal of Ethnomedicine, 1(4), pp. 244-249.

35. El Baky H. H. A., El Baroty G. S., Ibrahem E. A. (2015), Functional characters' evaluation of biscuits sublimated with pure phycocyanin isolated from Spirulina and Spirulina biomass, Nutricion Hospitalaria, 32(1), pp. 231-241.

36. Singh P., Singh R., Jha A., Rasane P., Gautam A. K. (2015), Optimization of a process for high fibre and high protein biscuit, Journal of Food Science and Technology, 52(3), pp. 1394-1403. 
37. Niccolai A., Venturi M., Galli V., Pini N., Rodolfi L., Biondi N., D’ottavio M., Batista A.P., Raymundo A., Granchi L., Tredici M.R. (2019), Development of new microalgaebased sourdough "crostini": functional effects of Arthrospira platensis (spirulina) addition, Scientific Reports, 9, pp. 1-12.

38. Barkallah M., Atitallah A.B., Hentati F., Dammak M., Hadrich B., Fendri I., Ayadi M.A., Michaud P., Abdelkafi S. (2019), Effect of Spirulina platensis biomass with high polysaccharides content on quality attributes of common Carp (Cyprinus carpio) and Common Barbel (Barbus barbus) fish burgers, Applied Sciences, 9, pp. 1-14.

39. Benzie I. F. and Strain J. J. (1996), The ferric reducing ability of plasma (FRAP) as a measure of 'antioxidant power': the FRAP assay, Analytical Biochemistry, 239 (1), pp. 70-76.

40. Tenorio-Rodriguez P. A., Murillo-Álvarez J. I., Campa-Cordova A. I., Angulo C. (2017), Antioxidant screening and phenolic content of ethanol extracts of selected Baja California Peninsula macroalgae, Journan of Food Science and Technology, 54 (2), pp. 422-429.

41. Velioglu Y., Mazza G., Gao L., Oomah B. (1998), Antioxidant activity and total phenolics in selected fruits, vegetables, and grain products, Journal of Agricultural and Food Chemistry, 46(10), pp. 4113-4117.

42. Aruoma O.I. (1998), Free radicals oxidative stress and antioxidants in human health and disease, Journal of the American Oil Chemists' Society, 75(2), pp. 199-212.

43. Malik P. (2011), Utilization of Spirulina powder for enrichment of ice cream and yoghurt, Animal and fisheries sciences university, Bidar.

44. Liang S., Liu X., Chen F., Chen Z. (2004). Current microalgal health food R \& D activities in China, Hydrobiologia, 512, pp. 45-48.

45. FAO, fisheries and aquaculture (2008), A review on culture, production and use of Spirulina as food for humans and feeds for domestic animals and fish. Circular No. 1034.

46. Herrero M., Martin-Alvarez P.J., Senorians F.J., Cifuentes A., Ibanez E. (2005), Optimization of accelerated solvent extraction of antioxidants from Spirulina platensis Microalga, Food Chemistry, 93, pp. 417-423.

47. Omidi S., Sarhadi H., Shahdadi F. (2018), Improvement of the oxidative stability of Sesame oil using Spirulina as a natural antioxidant, Journal of nutrition and food security, 3(4), pp. 209-217.

48. Bolanho B.C., Buranelo Egea M., Morocho Jácome A.L., Campos I., Monteiro De Carvalho J.C., Godoy Danesi E.D. (2014), Antioxidant and nutritional potential of cookies enriched with Spirulina platensisand sources of fibre, Journal of Food and Nutrition Research, 53 (2), pp. 171-179.

49. Auezova L., Najjar F., Selivanova O., Moussa E. H., Assaf M. D. (2013), Antioxidant activity of brown alga Saccharina bongardiana from Kamchatka (Pacific coast of Russia), A methodological approach, Journal of Applied Phycology, 25(4), pp. 11891196.

50. Heo S. J. and Jeon Y. J. (2008), Radical scavenging capacity and cytoprotective effect of enzymatic digests of Ishige okamurae, Journal of Applied Phycology, 20, pp. 10871095.

51. Senevirathne M., Kim S. K., Siriwardhana N., Ha J. H., Lee K.W., Jeon Y. J. (2006), Antioxidant potential of Ecklonia cava on reactive oxygen species scavenging, metal chelating, reducing power and lipid peroxidation inhibition, Food Science and Technology International, 12, pp. 27-38.

52. Wang T., Jónsdóttir R., Ólafsdóttir G. (2009), Total phenolic compounds, radical scavenging and metal chelation of extracts from Icelandic seaweeds, Food Chemistry, 116, pp. 240-248. 
53. Kumar M., Kumari P., Trivedi N., Shukla M. K., Gupta V., Reddy C. R. K., Jha B. (2011), Minerals, PUFAs and antioxidant properties of some tropical seaweeds from Saurashtra coast of India, Journal of Applied Phycology, 23, pp. 797-810.

54. Dutot M., Fagon R., Hemon M., Rat P. (2012), Antioxidant, anti-inflammatory, and antisenescence activities of a phlorotannin-rich natural extract from brown seaweed Ascophyllum nodosum, Applied biochemistry and biotechnology, 167(8), pp. 22342240.

55. Holdt S.L., Kraan S. (2011), Bioactive compounds in seaweed: Functional food applications and legislation, Journal of Applied Phycology, 23, pp. 543-597.

56. Kuda T., Tsunekawa M., Goto H., Araki Y. (2005), Antioxidant properties of four edible algae harvested in the Noto Peninsula, Japan, Journal of Food Composition and Analysis, 18(7), pp. 625-633.

57. Machu L., Misurcova L., Ambrozova J. V., Orsavova J., Mlcek J., Sochor J., Jurikova T. (2015), Phenolic content and antioxidant capacity in algal food products, Molecules, 20(1), pp. 1118-1133.

58. Thomas N. V., Kim S. K. (2013), Beneficial effects of marine algal compounds in cosmeceuticals, Mar Drugs, 11(1), pp. 146-164.

59. Sanjeewa K.K.A., Kim E.A., Son K.T., Jeon Y.J. (2016), Bioactive properties and potentials cosmeceutical applications of phlorotannins isolated from brown seaweeds: A review, Journal of Photochemistry and Photobiology B: Biology, 162, pp. 100-105.

60. Mannino A.M., Vaglica V., Cammarata M., Oddo E. (2016), Effects of temperature on total phenolic compounds in Cystoseira amentacea (C. Agardh) Bory (Fucales, Phaeophyceae) from southern Mediterranean Sea, Plant Biosystems, 150, pp. 152-160.

61. Cruces E., Rojas-Lillo Y., Ramirez-Kushel E., Atala E., López-Alarcón C., Lissi E., Gómez I. (2016). Comparison of different techniques for the preservation and extraction of phlorotannins in the kelp Lessonia spicata (Phaeophyceae): Assays of DPPH, ORACPGR, and ORAC-FL as testing methods, Journal of Applied Phycology, 28(1), pp. 573580.

62. Esteban R., Balaguer L., Manrique E., Rubio de Casas R., Ochoa R., Fleck I., PintóMarijuan M., Casals I., Morales D., Jiménez M.S., Lorenzo R., Artetxe U., Becerril J.M., García-Plazaola J.I. (2009), Alternative methods for sampling and preservation of photosynthetic pigments and tocopherols in plant material from remote locations, Photosynthesis Research, 101(1), pp. 77-88.

63. Mekini'c I.G., Skroza D., Šimat V., Hamed I., Čagalj M., Perkovi'c Z.P. (2019), Phenolic Content of Brown Algae (Pheophyceae) Species: Extraction, Identification, and Quantification, Biomolecules, 9(6), pp. 1-25.

64. Lebska T., Ochkolias O. (2016), Influence of algae on the change of butter quality indicators, Ukrainian Journal of Food Science, 4(1), pp. 40-48.

65. Chirinos R., Rogez H., Campos D., Pedreschi R., Larondelle Y. (2007), Optimization of extraction conditions of antioxidant phenolic compounds from mashua (Tropaeolum tuberosum Ruíz \& Pavón) tubers, Separation and Purification Technology, 55(2), pp. $217-225$.

66. Lopez A., Rico M., Rivero A., De Tangil M. S. (2011), The Effects of Solvents on the Phenolic Contents and Antioxidant Activity of Stypocaulon scoparium Algae Extracts, Food Chemistry, 125(1), pp. 1104-1109. 